\title{
Is it possible to engage adolescents in community-based non- communicable disease programs?: A case study in a rural area in Yogyakarta
}

\author{
Fitrina Kusumaningrum ${ }^{1,2^{*}}$, Fahmi Baiquni', Cati Martiyana ${ }^{3}$, Luqman Afifuddin', Dita Anugrah \\ Pratiwi ${ }^{1}$, and Ida Susanti ${ }^{1}$
}

'Department of Health Behavior, Environment, and Social Medicine, Faculty of Medicine, Public Health and Nursing, Universitas Gadjah Mada, Yogyakarta, Indonesia

${ }^{2}$ Center for Health Behavior and Promotion, Faculty of Medicine, Public Health and Nursing, Universitas Gadjah Mada, Yogyakarta, Indonesia

${ }^{3}$ Magelang Research and Development Center, Ministry of Health, Indonesia

\section{KEYWORDS}

Community-based program

Community empowerment

Non-communicable diseases
ABSTRACT Adolescents are a potential segment of society to be involved in health programs. However, adolescent involvement in community-based health programs is limited, especially for non-communicable diseases. This study explores adolescents' participation in communitybased non-communicable disease programs in a rural area of Indonesia, and factors that enable or hinder their engagement. This was a qualitative case study using the data of the Hypertension Responsive Village Movement (HRVM) Program, a community empowerment program for hypertension control in Sleman Regency, Yogyakarta. Participants consisted of adolescents aged 12 to 25 years old who are involved in HRVM. The data analyzed consisted of attendance lists and meeting/activity minutes of 6 adolescents' programs, transcripts of interviews with 2 community leaders (village head and youth organization leader), resume of a group discussion with adolescents' representatives, video records of adolescent programs activities and field notes. Thematic data analysis was conducted to describe adolescents' participation, as well as the barriers and enabling factors. Descriptive analysis of attendance lists and meeting/ activity minutes was developed to describe the retention rate of adolescents in the program. Adolescents' form of participation ranged from being an acceptor to initiator. In the beginning of the program, 20 adolescents participated. However, by the end of the program, only 8 (40\%) adolescents remained. Enabling factors for engagement were the community leaders' supports, the adjustment of program strategies and deliveries with adolescence needs and the availability of social capital in the form of youth organizations. The barriers were adolescents' limited time and limited adolescents' participation in youth organization. In conclusion, engaging adolescents in community-based programs is possible even though it provides some challenges because of the limited time adolescents spend in their community. Strengthening stakeholders' support, adjusting program strategies and deliveries with target characteristics and utilizing social capital are important to engage adolescents in community-based programs.

(c) The Journal 2021. This article is distributed under a Creative Commons Attribution-ShareAlike 4.0 International license.

\section{Introduction}

Data from the Central Bureau of Statistics Indonesia in 2019 showed that approximately $25 \%$ of the Indonesian population are aged $10-24$ years old. ${ }^{1}$ As one of the significant proportions of the Indonesian population, adolescents have the potential to be empowered, especially in non-communicable

*Correspondence: fitrina.m.k@gmail.com

Department of Health Behaviour, Environment, and Social Medicine, Faculty of Medicine, Public Health, and Nursing, Universitas Gadjah Mada, J. Farmako, Sekip Utara, Yogyakarta 55281, Indonesia disease (NCD) prevention programs. However, adolescents are seen to have a low risk of disease and health interventions are limited to certain specific topics, such as mental health, reproductive health, violence and drug abuse. Whereas, adolescents' behavior will affect their health conditions during their productive and elder age. ${ }^{2}$ Studies also showed that the prevalence of NCDs such as hypertension in adolescents is undiagnosed because of the absence of symptoms or difficulty in recognizing symptoms. Interventions regarding NCDs and their risk factors need to be introduced early since adolescence. ${ }^{3}$ 
Reviews showed there are limited health interventions aimed at adolescents in the community, although these interventions are known to be effective in changing youth behavior and ensuring program sustainability. ${ }^{4,5}$ Meanwhile, most interventions for adolescents in lower or middle-income countries are focused on educational institution settings. This gap is a serious concern because interventions at the community level ensure the equity in the health system. ${ }^{6}$

Engaging adolescents in health programs also faces its own challenges, for example, their low level of participation in these community programs. Research in Makassar and Jakarta on drug abuse control programs showed low (<20\%) participation among adolescent. ${ }^{7}$ Another study also showed that less than $25 \%$ of adolescents in Makassar utilize reproductive health services. This pattern is due to the limited knowledge of adolescents concerning existing health issues and services. ${ }^{8}$ In addition, some interventions for adolescents do not focus on outcomes at the level of participation, ${ }^{9}$ making it difficult to identify the barriers and enabling factors of adolescents' engagement.

The Hypertension Responsive Village Movement (HRVM) is a community empowerment intervention aimed to prevent hypertension and its risk factors. This youth program was developed in Pundong II village, Tirtoadi, Mlati, Sleman, Special Region of Yogyakarta in 2017, and is part of an integrated community empowerment program at the Faculty of Medicine, Public Health and Nursing (FM-PHN), Universitas Gadjah Mada (UGM). Arnstein (2019) emphasized that optimal participation is achieved when the community has the ability and opportunity to make decisions or can fully manage their own resources. ${ }^{10}$ The HRVM program is particularly interesting to be studied because of its characteristics that involve adolescents by providing opportunities for planning and developing the expected programs. This study aimed to explore adolescents' participation in the HRVM Program in Pundong II village, Sleman, as well as the barriers and supporting factors, so that the lessons learnt can be identified and promoted for similar program development.

The Hypertension Responsive Village Movement
(HRVM) is a community-based hypertension prevention program which is targeted toward three groups in the community: the elderly, productive age citizens, and adolescents. The process of developing the program started with the basic steps of community revitalization: problem analysis, determining priority problems, planning and implementing programs and evaluation. The data collection in HRVM aimed to evaluate the effectiveness of the program, which measured increases in knowledge of hypertension and risk factors, and explored participants' engagement in the program. Data were collected using quantitative and qualitative methods among 43 participants, consisting of 20 adolescents, 11 cadres and community leaders, and 12 lay people from January to December 2017. Quantitative data were collected through surveys developed to measure participants' knowledge regarding hypertension and risk factors before and after health education. Qualitative data were collected through in-depth interviews with five community leaders and cadres, and observations of program activities aimed to explore participants' engagement and create evaluations regarding the HRVM program. Every activity of the intervention was documented using standardized forms that record the overall process of activities, specific points of discussion and/or results of the intervention and identified follow-up action plans if available. Some activities were also recorded using a video recorder with participants' permission. This study focused on the HRVM implemented for adolescents (12 to 25 years old). A detailed description of the program implemented for other targets is published elsewhere. ${ }^{11}$

There were two main issues raised in the program for adolescents: 1) increasing physical activity and 2) increasing knowledge about hypertension. The selection of these issues was based on a needs analysis conducted by the program manager and community leaders. Adolescents' engagement process in the program consisted of four phases described in Figure 1. The first phase of adolescent engagement in HRVM was implemented to gain stakeholder trust and support. Stakeholders involved in this phase included the heads of the village, cadres, head of youth organization and heads of neighborhood units. Program implementers 


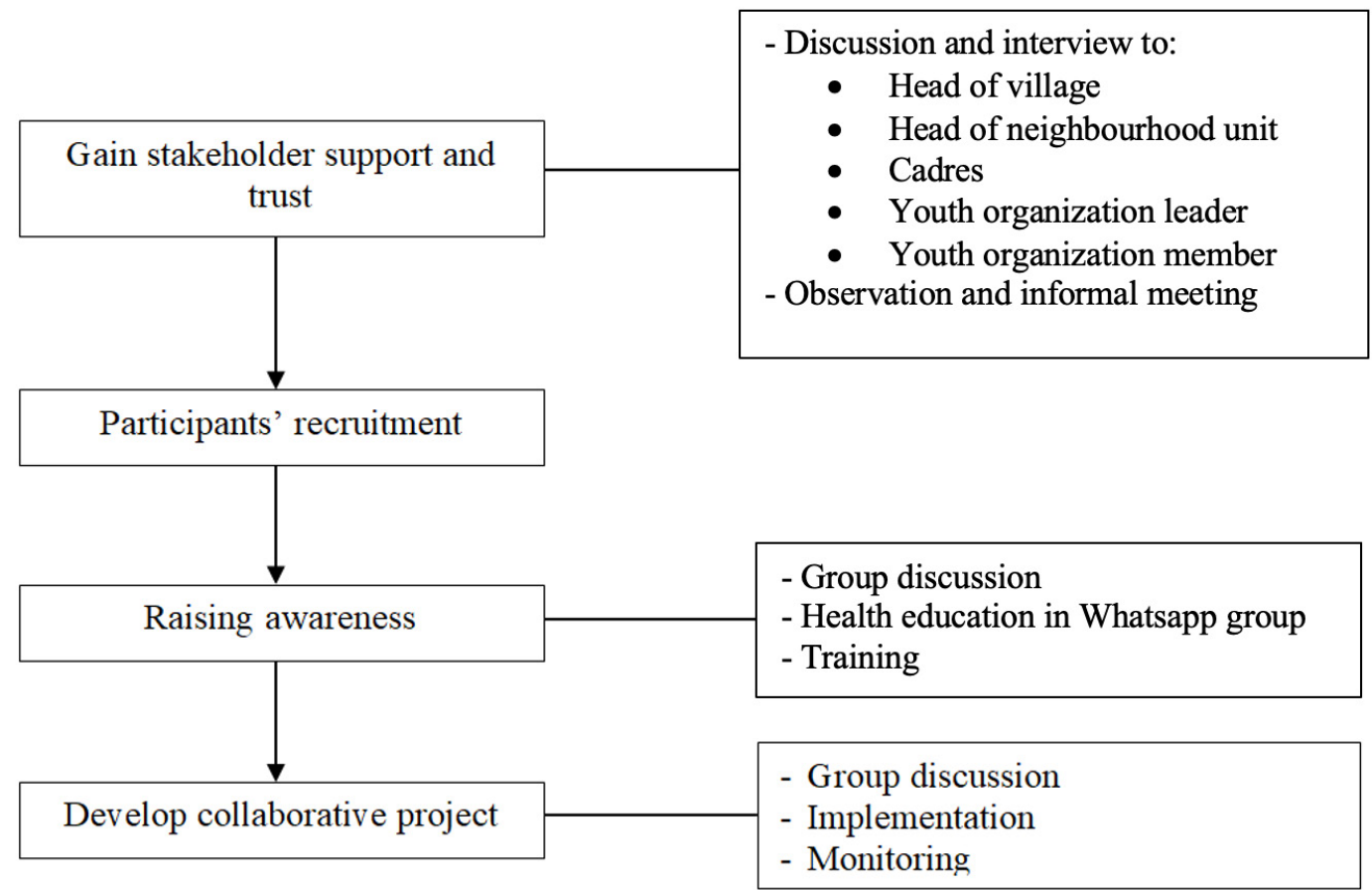

Figure 1. Adolescents' engagement process in HRVM

conducted observations and discussion with village leaders, heads of neighborhood units and cadres regarding the possibility to involve adolescents in the program and the HRVM representatives initially approached the youth organization leaders. Program implementers also approached the members of youth organizations and adolescents in an informal setting to get acquainted and gain their trust. This process was conducted approximately for two months.

The second phase in adolescents' engagement process was directed toward recruiting participants. The total population of adolescents in Pundong II village is about 40 people. However, not all of them were involved in the program because of scheduling conflicts. Participants' recruitment was assisted by youth organization leaders and started in the youth organization meeting. During the meeting, program implementers facilitated the discussion of health issue and explored adolescents' views regarding hypertension and risk factors. Program implementers shared their plan on conducting health education and asked them to join the program.

After recruitment, participants were involved in group discussions and health education. Health education and group discussions were held in faceto-face meetings and a WhatsApp group. Program implementers also held a training to train adolescents in measuring their blood pressure. This phase acted as the lever to develop the collaborative project.

In phase four, program implementers held a meeting to explore adolescents' views regarding follow-up actions. From the four risk factors of hypertension (physical inactivity, unhealthy diet, smoking behavior and obesity), adolescents choose to increase physical activity as their collaborative project. Program implementers facilitated three group discussions on how to increase physical activity and the adolescents initiated a plan to activate a community biking group as their collaborative project. They held collective actions to bike together at night and promote the activity to other adolescents who were physically inactive. As part of the collaborative project, program implementers suggested developing health education media, such as posters and promotional media. Meetings to monitor the implementation of the collaborative project were held twice during the programs.

\section{Method}


Table 1. Form of participation, enabling factors and barriers of adolescents' engagement in HRVM

\begin{tabular}{|c|c|}
\hline Themes & Categories \\
\hline Forms of Participation & $\begin{array}{ll}\text { - } & \text { Acceptor } \\
\text { - } & \text { Implementer } \\
\text { - } & \text { Reviewer } \\
\text { - } & \text { Initiator } \\
\text { - } & \text { Planner }\end{array}$ \\
\hline Enabling Factors & $\begin{array}{ll}\text { - } & \text { Stakeholder supports } \\
\text { - } & \text { Strategies and program } \\
& \text { deliveries } \\
\text { - } & \text { Community's social capital }\end{array}$ \\
\hline Barriers & $\begin{array}{ll}\text { - } & \text { Time } \\
\text { - } & \text { Involvement in organizations }\end{array}$ \\
\hline
\end{tabular}

This research was a qualitative case study using secondary data of HRVM to explore adolescents' participations, barriers and enabling factors. Even though qualitative secondary data analysis typically will face many criticisms regarding its rigor, this method is still seen as potentially beneficial to be developed as long as the researchers maintain the relevancy of the data, for example, by identifying and documenting the context when the data were collected. ${ }^{12}$ Qualitative methods in this study were developed using a case study approach by exploring a case through multiple sources of reporting. ${ }^{13}$

\subsection{Participants and research data}

Participants in this study were adolescents and stakeholders who participated in HRVM in 2017. The Hypertension Responsive Village Movement (HRVM) program recruited adolescent participants purposively using the following inclusion criteria: 1) resident of Pundong II village, Mlati, Sleman, Yogyakarta; 2) age 12 to 25 years old; and 3) willing and permitted by parents to participate in the HRVM program. There were 20 adolescents who participated in the program and became the sample of this research. In addition, transcripts of stakeholders (heads of the village and youth organization leaders) from two interviews were also analyzed in this research.

Data analyzed in this research consisted of attendance lists and meeting/activity minutes of 6 programs (see Table 1) for adolescents, transcripts of interviews with 2 community leaders (village head and youth organization leader), resume of a group discussion with adolescents' representatives, video records of adolescent programs activities and field notes. The HRVM reports explained the results of the overall HRVM program (program effectiveness for all of the targets). ${ }^{11}$ Meanwhile, this research was focused to explore adolescent participations, the barriers, and also the enabling factors.

\subsection{Setting}

The HRVM program was conducted in Pundong II village, Tirtoadi, Mlati, Sleman Regency, Special Region of Yogyakarta, Indonesia in January to December 2017. Pundong II village is a rural area in Sleman Regency Yogyakarta with a total population of 316 people ( $50.3 \%$ men). Pundong II village is divided into four neighborhoods (Rukun Tetangga/ RT) to facilitate the administration process. Pundong II village has the unique characteristics of high social capital of its community. It is shown by the availability of community organizations such as the youth organization (karang taruna), village consultative council (lembaga permusyawaratan masyarakat desa/LPMD) and family welfare movement (pemberdayaan kesejahteraan keluarga) PKK). Community meetings in the neighborhood unit also conducted monthly meetings to discuss problems that arise around their neighborhood.

\subsection{Data collection}

All of the program implementers and data collectors of HRVM program are also researchers in this study. All of the researchers are health promotion practitioners with a master of public health background. Researchers 4, 5, 6 and 7 were students of the magister program of public health in FMHPN, Universitas Gadjah Mada during the program implementation and data collection. Researchers 4, 5, 6 and 7 implemented the program and collected data as a part of their coursework with supervision from researcher 2 and guidance from researcher 1 . After the program, researchers 1 and 2 compiled and reviewed all HRVM data and documents. The documents and data that were suitable to answer the research questions were chosen and analyzed 
to explore adolescents' participation in the program, barriers and also enabling factors. The results of the analysis were discussed with researchers 4, 5, 6 and 7. Any conflicting interpretations regarding the data were discussed until reaching consensus to ensure trustworthiness. The use of HRVM data in this study had been approved by all involved parties.

\subsection{Data analysis}

Secondary data collected in this research were analyzed using thematic analysis. Before analyzing, researchers 1 and 2 reviewed the chosen data and documents to get familiar with the data. Researchers took notes for the data that needed further confirmation and these were confirmed with the data collectors. Researchers also developed observation notes from meeting/activity recordings. Researchers then developed meaning units and developed categories/subthemes from the identified codes using software OpenCode 4.03. Categories/ subthemes were grouped based on the predetermined themes: 1) forms of participation; 2) enabling factors for engagement and 3 ) barriers for engagement. Data analysis resulted in three themes and ten categories.

\subsection{Ethical consideration}

This study protocol was reviewed by the Medical and Health Research Ethics Committee of the Faculty of Medicine, Public Health and Nursing, Universitas Gadjah Mada and approved with the letter Ref. No.:
KE/FK/0010/EC/2021.

\section{Result}

Data analysis resulted in eleven categories that were grouped into three themes. Details of the themes and categories are described in Table 1.

\subsection{Forms of participation}

There were 20 adolescents who participated in the beginning of the program. However, only 8 adolescents (40\%) remained involved until the conclusion. Most of the participants were males, who had already finished junior high school and in the age range of 16 to 20 years-old. The distribution of participants' age groups was uneven because most participants were more than 18 years old, were already working or moved to another city to pursue bachelor degree. Details of participants' characteristics are described in Table 2.

Adolescents' participation in HRVM program was manifested in many forms. Data analysis showed that there were six forms of adolescents' participation in the program. As acceptors, these adolescents participated in the program by seldomly sharing their ideas or thoughts regarding the program delivery or the program contents. Some examples of these programs were health education regarding hypertension and media development.

Another form of adolescents' participations was as an implementer, where adolescents implemented

Table 2. Demographic characteristics of adolescent participants in HRVM program

\begin{tabular}{lllll}
\hline \multirow{2}{*}{ Demographic Characteristics } & Early Program & \multicolumn{2}{c}{ End Program } \\
\cline { 2 - 5 } & $\mathbf{n}$ & $\mathbf{0}$ & $\mathbf{n}$ & \% \\
\hline Sex & 12 & 60 & 6 & 75 \\
Men & 8 & 40 & 2 & 25 \\
Women & & & 2 & 25 \\
Age & 3 & 15 & 4 & 50 \\
$11-15$ y.o. & 11 & 55 & 2 & 25 \\
$16-20$ y.o. & 6 & 30 & & 0 \\
$21-25$ y.o & & & 0 & 87.5 \\
Education level & 1 & 5 & 7 & 0 \\
Elementary school & 13 & 65 & 0 & 12.5 \\
Junior high school & 4 & 20 & 1 & \\
Senior high school & 2 & 10 & & \\
Bachelor degree & & & & \\
\hline
\end{tabular}


the program, shared their resources and evaluated the program. All of the programs that were implemented by adolescents in HRVM were also designed by them, including the discussion, dissemination of media and collective actions to improve their physical activity. In the development of collective action to improve their physical activity, adolescents also initiated the activation of a biking group as a collaborative project.

Adolescents in HRVM also participated as a reviewer of the media development regarding hypertension and physical activity. In this program, program implementers generated the ideas to develop the media, the message and the design. Program implementers asked participants' opinions regarding the message and the design of the media. When approved, the program implementers gave the media to the participants to be disseminated in their neighborhood. The mapping of adolescents' various forms of participation in HRVM is described in Table 3.

\subsection{Enabling factors of adolescents' engagement}

There were four main factors that served as enablers of adolescents' engagement in HRVM. The first enabling factor was support from the community stakeholders. Community leaders such as the head of the village, heads of the neighborhood unit, cadres, heads and members of youth organizations, all encouraged the adolescents to become involved in the program. During program monitoring, community leaders also gave suggestions concerning the ways to involve adolescents in the program and gave solutions to problems encountered during the program implementation. Community leaders held the shared view that HRVM could benefit the community, therefore, they encouraged more community involvement in the program. Data from field notes and monitoring showed that community leaders encouraged adolescents to be involved in the programs.

Other enabling factors are the actual strategies and program deliveries. The HRVM program for adolescents was developed using both offline and online meetings. For online discussion, HRVM used the WhatsApp platform to share information regarding hypertension, risk factors and prevention. The head of youth organization viewed the use of WhatsApp group as a way to provide an opportunity for adolescents to become involved in the programs. The program implementer not only applied health education strategies but also helped in developing collaborative projects to encourage more participation from the adolescents.

During the implementation, the program implementer relied on the youth organization to gain trust and casually approached the adolescents in the study area. The program implementer reflected the availability of social capital in the form of the youth

Table 3. Description of adolescents' form of participation in HRVM

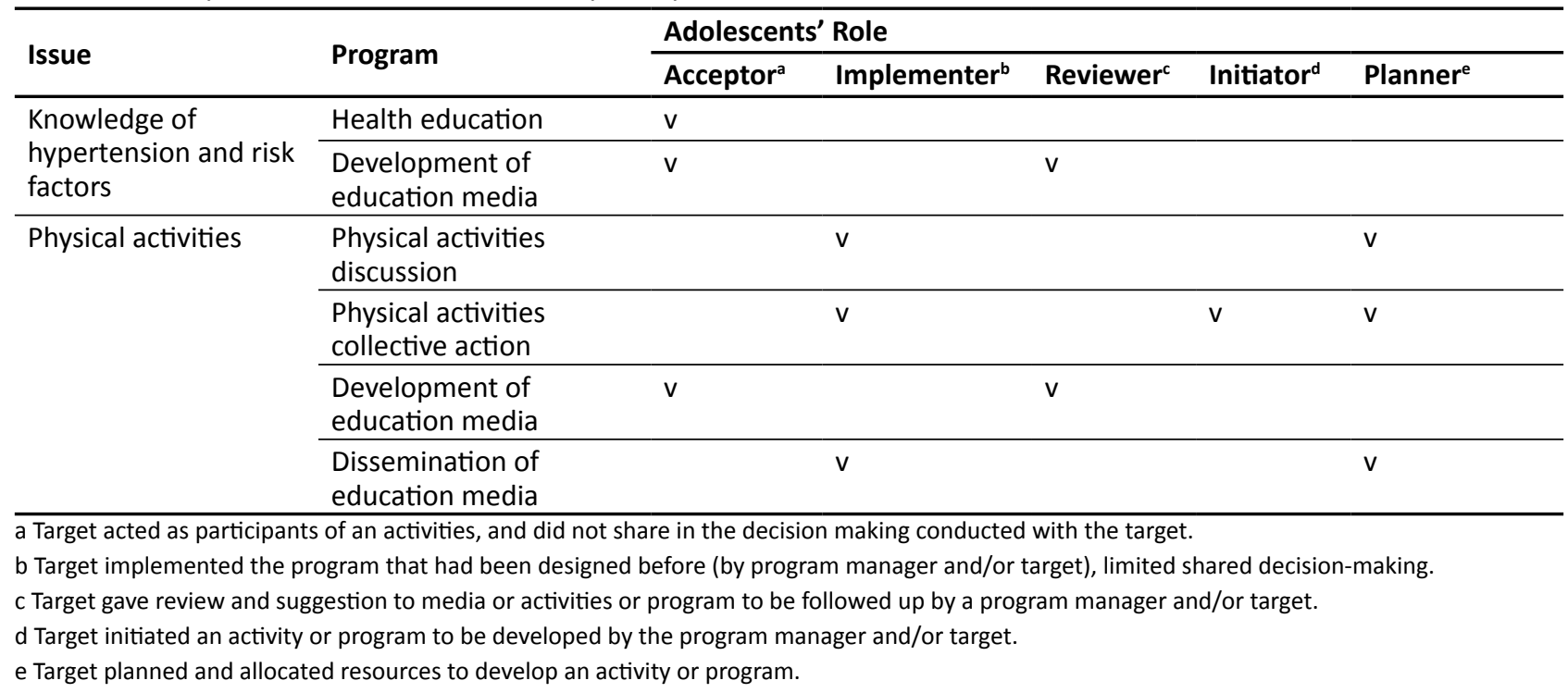


organization and the cohesiveness of the community which played an essential part in encouraging adolescents to participate in the program. Youth organization members also encouraged other adolescents to be involved in the program. Observation results showed that the heads of youth organization were capable to organize adolescents in the study area to participate in the program.

\subsection{Barriers of adolescents' engagement}

There were two barriers for adolescents' engagement identified in this study. Time became the main barrier because adolescents in the study area underwent their mid-semester test during the program implementation, therefore, they preferred to study rather than get involved in the program. Sometimes, there were also community activities that were held at the same time with the program that hindered the adolescents to participate. Adolescents aged $18+$ also experienced schedule conflicts with their working activities or college activities. The following quotes describe adolescents' schedule conflicts when participating in health education program: "Sorry brothers, sisters, sorry for the slow response,... the problem is, now there is a meeting in my place,, (we are) deeply sorry, and all of the guys are busy (preparing) the activity in my place" However, the program implementer and youth organization leader tried to negotiate the schedule, keep participants informed about the program and included those who were unable to participate offline in the WhatsApp group for health education.

Another barrier of adolescent engagement was the small number of adolescents who participated in the youth organization. The youth organization leader shared that not all of the adolescents were involved actively in youth organization. Therefore, those adolescents who were not involved in the youth organization did not often join in the program. To overcome this barrier, the program implementer tried to inform them about the program with the help of the head of neighborhood unit.

\section{Discussion}

This study showed that adolescents can participate in a community-based NCD program with a wide range of roles from acceptor to initiator of the program. Engaging adolescents in community-based programs should take into account the stakeholder supports, strategies and program deliveries and community's social capital. However, people who wish to engage adolescents in community-based program should consider the time available for adolescents to participate and their involvement in the communitybased organization.

Our study showed that engaging adolescents in NCD community-based programs is possible through community engagement strategies such as partnership and developing collaborative projects. In many countries, adolescents are barely involved in community planning and programs, even though the program affects their well-being and status. This trend happens because adolescents have been viewed as lacking power and incapable to make good decisions because of lack of knowledge and skills. ${ }^{14,15}$ Community engagement strategies can be utilized in health programs and research to increase involvement, ${ }^{16}$ with the main components including comprehensive need assessment, collaborative partnership, real power-sharing and ensuring shared decision-making between authority/stakeholders and community. ${ }^{17,18}$ Another study also showed that by providing opportunities to share opinions, building adolescents' capacity, encouraging youthful styles of working and developing tasks that focus on shortterm goals could improve adolescent engagement. ${ }^{5,14}$

Arnstein (1969) stated that the distribution of power is an important component of citizen participation. The highest level of citizens' participations happens when citizens have control over their resources and decision-making process. ${ }^{10}$ In adolescents, the highest level of adolescents' participation is defined when they share the power/ responsibility, initiate the development of the program and are able to make decisions regarding the program. ${ }^{15,19,20}$ Adolescents' engagement in HRVM was manifested in a wide range of roles. Therefore, we cannot state that this program had achieved the highest level of participation. One review regarding intervention programs among adolescents found that studies which encourage the highest level of participation in adolescents were very limited. This pattern occurs because adolescents should be 
involved from the very beginning of the research, including when forming the research questions. ${ }^{19}$

Our study also showed that stakeholder support and communities' social capital play an important part in encouraging adolescents to participate in the program. Support from stakeholders was achieved by gaining trust from the community. In his review, Wilkins (2018) stated that gaining trust is important in the engagement process. In gaining trust, the researchers should communicate honestly, empathetically and be accessible and approachable to participants. ${ }^{21}$ The process to gain trust in the HRVM Program was conducted through discussion and involved approaching to stakeholders in informal setting. These kinds of interactions are important to understand and build strong relationships between each party and develop commitment with the project. $^{22}$

Characteristics of program deliveries and strategies become the enabling factors in our study. The use of multi-platform and multi-strategies could be an alternative to encourage adolescents' engagement in the program. Application of more than one strategy is known to increase the effectiveness of a program and boost participation in a community-based program. ${ }^{23,24}$ The use of a youthful approach and multimedia through social media or television are also known to promote engagement in adolescents because it can improve their opportunity to share their voices and creativity. ${ }^{14,25}$ Further study in community-based programs should consider the target and explore the suitable strategies to ensure community engagement in the program.

Institutions such as schools are an effective setting in delivering health programs to adolescents. ${ }^{26}$ However, the program implementer should also consider the need of adolescents who are not in the school setting to ensure equity in health service. ${ }^{6}$ Our results also showed that adolescents face barriers in participating community-based programs, and one of them was regarding adolescents' limited time in the community. Another study also reported the same barrier when implementing community-based programs for adolescents. ${ }^{27}$ Strategies to overcome those barriers include involving the families in the program, using an on-line platform or making the program more enjoyable for adolescents. Further studies should explore the possibility to involve family members in the program and employ an enjoyable package of intervention to ensure the retention of adolescents in the community-based program. ${ }^{23}$

The HRVM program was focused on preventing hypertension and the risk factors in a community setting. Our study showed that adolescents can be a part of community-based interventions on NCDs. Enabling factors include stakeholder supports, community's social capital and strategies and program deliveries that encourage adolescents' participation, in our case by developing collaborative projects and providing room for discussion. However, our study had some limitations. We did not analyze adolescents' views regarding the extent of their participation in the program because of the limited data available. Exploration concerning participants' views and evaluations on the program are important to ensure the collaborative nature and also the sustainability of the program. ${ }^{5}$

\section{Conclusion}

Engaging adolescents in community-based programs is possible even though it provides some challenges because of the limited amount of time adolescents spent in their community. Strengthening stakeholders' support, adjusting program strategies and deliveries with target characteristics and utilizing social capital are important to engage adolescents in community-based programs.

\section{Acknowledgement}

This study is part of community service conducted by Department of Health Behavior, Environment and Social Medicine, Faculty of Medicine, Public Health and Nursing, Universitas Gadjah Mada that was funded by the community fund of Faculty of Medicine, Public Health and Nursing, Universitas Gadjah Mada in 2017.

\section{Conflict of interests}

There is no conflict of interest.

\section{References}


1. Badan Pusat Statistik. Proyeksi Penduduk Indonesia 2010-2035/BPS-Statistics Indonesia, 2010 Population Census and Indonesia Population Projection 2010-2035. Jakarta. 2013

2. Lule E, Rosen JE, Singh S, et al. Adolescent Health Programs. In: Jamison DT, Breman JG, Measham $A R$, et al., editors. Disease Control Priorities in Developing Countries. 2nd edition. Washington (DC): The International Bank for Reconstruction and Development / The World Bank; 2006. Chapter 59. Co-published by Oxford University Press, New York.

3. Ewald DR, Haldeman LA. Risk factors in adolescent hypertension. Global Pediatric Health. 2016;3: $2333794 X 15625159$.

4. Salam RA, Das JK, Lassi ZS, Bhutta ZA. Adolescent health interventions: conclusions, evidence gaps, and research priorities. J Adolesc Health. 2016; 59(4 Suppl):S88-S92.

5. Merves ML, Rodgers CRR, Silver EJ, Sclafane JH, Bauman LJ. Engaging and sustaining adolescents in community-based participatory research: structuring a youth-friendly CBPR environment. Fam Community Health. 2015;38(1):22-32.

6. Rose-Clarke K, Bentley A, Marston C, Prost A. Peer-facilitated community-based interventions for adolescent health in low- and middle-income countries: a systematic review. PLoS One. 2019 January; 23.

7. Riskiyani S, Sabarinah. Determinants of student participation in drug prevention programs in Jakarta and Makassar. KnE Life Sciences. 2018.4(1):264 - 271.

8. Violita F, Hadi EN. Determinants of adolescent reproductive health service utilization by senior high school students in Makassar, Indonesia. BMC Public Health. 2019; 19(286).

9. Agdal R, Midtgard IH, Meidell V. Can assetbased community development with children and youth enhance the level of participation in health promotion projects?: a qualitative metasynthesis. Int J Environ Res Public Health. 2019 Oct; 16(19): 3778.

10. Arnstein SR. A ladder of citizen participation. J Am Plann Assoc. 2019;85(1):24-34.

11. Martiyana C, Pratiwi DA, Susanti I, Afifuddin L. Laporan Implentasi dan Evaluasi Pelaksanaan
Kegiatan Gerakan Dukuh Tanggap Hipertensi (GDTH) Dukuh Pundong II, Desa Tirtoadi, Kecamatan Mlati, Kabupaten Sleman. 2017. Yogyakarta: Library of Post Graduate School of Public Health, Faculty of Medicine, Public Health and Nursing, Universitas Gadjah Mada

12. Ruggiano N, Perry TE. Conducting secondary analysis of qualitative data: Should we, can we and how? Qualitative Social Work. 2017 April; 18(1).

13. Creswell JW, Poth CN. Qualitative Inquiry and Research Design: Choosing Among Five Approaches. 2017. USA: SAGE Publications, Inc.

14. Frank KI. The potential of youth participation in planning. J Plan Lit. May 2006; 20(4).

15. Cahill H \& Dadvand B. Re-conceptualising youth participation: a framework to inform action. Child Youth Serv Rev. 2018; 95: 243-253.

16. Ahmed SM, Palermo AS. Community engagement in research: frameworks for education and peer review. Am J Public Health. August 2010; 100(8).

17. Cyrill S, Smith BJ, Possamai-Inesedy A, Rensaho AMN. Exploring the role of community engagement in improving the health of disadvantaged populations: a systematic review. Glob Health Action. 2015; 8.

18. De Weger E, Van Vooren N, Luijkx KG, Baan CA, Drewes HW. Achieving successful community engagement: A rapid realist review. BMC Health Serv Res. 2018;18(1):1-18.

19. Larsson I, Staland-Nyman C, Svedberg P, Nygren JM, Carlson I. Children and young people's participation in developing interventions in health and well-being: a scoping review. BMC Health Serv Res. 2018; 18:507.

20. Hart RA. Stepping Back from 'The Ladder': Reflections on a Model of Participatory Work with Children in Reid A, Jensen B, Nikel J, Simovska V. (eds) Participation and Learning: Developing Perspectives on Education and the Environment, Health and Sustainability. (pp.19-31). Chapter 2. UK: Springer.

21. Wilkins $\mathrm{CH}$. Effective engagement requires trust and being trustworthy. Med Care. Oct 2018; 56 (10 Suppl 1): S6 - S8.

22. Christopher S, Watts V., McCormick A., Young S. 
Building and maintaining trust in a communitybased participatory research partnership. American Journal of Public Health. August 2008; 98(8): 1398 - 1406

23. Smith KL, Straker LM, McManus A, Fenner AA. Barriers and enablers for participation in healthy lifestyle programs by adolescents who are overweight: a qualitative study of the opinions of adolescents, their parents and community stakeholders. BMC Pediatr. 2014; 14(53).

24. Glanz K, Rimer BK, Viswanath K. Health Behavior and Health Education. 2008. San Francisco: John Wiley \& Sons.
25. UNICEF. Adolescent and Youth Engagement Strategic Framework. 2017. New York: UNICEF

26. Shackleton N, Jamal F, Viner RM, Dickson $K$, Patton G, Bonell C. School-based interventions going beyond health education to promote adolescent health: systematic review of reviews. J Adolesc Health. Apr 2016; 58(4): 382 - 396.

27. Morgan K, Godwin JV, Darwent K, Fildes A. Formative research to develop a school-based, community-linked physical activity role model programme for girls: Choosing Active Role Models to Inspire Girls (CHARMING). BMC Public Health. 2019; 19(437). 